\title{
Quercetin Upregulates Uncoupling Protein 1 in White/Brown Adipose Tissues through Sympathetic Stimulation (J Obes Metab Syndr 2018;27:102-9)
}

\author{
Hyunjung Choi, Chu-Sook Kim, Rina Yu* \\ Department of Food Science and Nutrition, University of Ulsan, Ulsan, Korea
}

\author{
Received March 8, 2019 \\ Reviewed March 10, 2019 \\ Accepted March 13, 2019 \\ ${ }^{*}$ Corresponding author \\ Rina Yu \\ https://orcid.org/0000-0002-1965-389 \\ Department of Food Science and \\ Nutrition, University of Ulsan, \\ 93 Daehak-ro, Nam-gu, Ulsan 44610, \\ Korea \\ Tel: +82-52-259-2372 \\ Fax: +82-52-259-1698 \\ E-mail: rinayu@ulsan.ac.kr
}

Uncoupling protein 1 (UCP1) plays an important role in increasing energy expenditure and is considered as a new target for preventing obesity and metabolic complications. Quercetin elicits protective effects against obesity-induced peripheral/central inflammation and metabolic dysregulations. ${ }^{1-4}$ Our previous study ${ }^{5}$ showed that dietary quercetin supplementation increased the level of UCP1 in white adipose tissue (WAT) and/or brown adipose tissue (BAT) of high-fat diet (HFD)-fed obese mice and was accompanied by upregulated mRNA levels of thermogenesis-related genes. Quercetin supplementation enhanced the plasma norepinephrine level and tended to upregulate $\beta 3$-adrenergic receptor mRNA level in the WAT of HFD-fed obese mice, accompanied by AMP-activated protein kinase (AMPK) activation. Subsequently, we showed that quercetin-induced UCP1 expression was blunted by a peroxisome proliferator-activated receptor gamma (PPAR $\gamma)$ antagonist in 3T3-L1 adipocytes. Based on these findings, we concluded that quercetin upregulated UCP1, leading to increased WAT browning and BAT activity, and the quercetin action was associated with activation of the AMPK/PPAR $\gamma$ pathway through norepinephrine-associated sympathetic stimulation.

We agree with the view that the quercetin action on UCP1 induction in the adipose tissue may involve other mechanisms inde- pendent of norepinephrine-associated sympathetic stimulation. As suggested, experiments using $\beta$-adrenergic receptor blocker may be helpful to confirm quercetin action through sympathetic stimulation in HFD-fed obese mice. A recent study has shown that quercetin-3-O-glucuronide, a major metabolite of quercetin, blocks norepinephrine-induced $\alpha 2$ - and $\beta 2$-adrenergic signals ${ }^{6}$, which are responsible for cardiovascular effects such as increased heart rate and blood pressure. Interestingly, similar to $\beta 2$-adrenegic receptor, stimulation of $\beta 3$-adrenergic receptor increases the generation of cyclic AMP and the activation of protein kinase A; however, it is likely that $\beta 3$-adrenergic receptor stimulation suppresses $\beta 2$ adrenergic receptor over-activation in the myocardium. ${ }^{7,8}$ Hence, it is tempting to speculate that quercetin may enhance UCP1 in the adipose tissues through norepinephrine-mediated $\beta$-adrenergic receptor activation without adverse cardiovascular effects. Further studies are needed to determine how quercetin enhances plasma norepinephrine and $\beta 3$-adrenergic receptor $\mathrm{mRNA}$ in the adipose tissues, as well as the stress issue.

\section{CONFLICTS OF INTEREST}

The authors declare no conflict of interest. 


\section{REFERENCES}

1. Kim CS, Yu R. The inhibitory effect of quercetin on adipose tissue inflammation in mice fed on a high-fat diet. Korean J Obes 2014;23:170-8.

2. Le NH, Kim CS, Park T, Park JH, Sung MK, Lee DG, et al. Quercetin protects against obesity-induced skeletal muscle inflammation and atrophy. Mediators Inflamm 2014;2014:834294.

3. Kim CS, Kwon Y, Choe SY, Hong SM, Yoo H, Goto T, et al. Quercetin reduces obesity-induced hepatosteatosis by enhancing mitochondrial oxidative metabolism via heme oxygenase-1. Nutr Metab (Lond) 2015;12:33.

4. Yang J, Kim CS, Tu TH, Kim MS, Goto T, Kawada T, et al. Quercetin Protects obesity-induced hypothalamic inflammation by reducing microglia-mediated inflammatory responses via HO-1 induction. Nutrients 2017;9:650.

5. Choi H, Kim CS, Yu R. Quercetin upregulates uncoupling protein 1 in white/brown adipose tissues through sympathetic stimulation. J Obes Metab Syndr 2018;27:102-9.

6. Yamazaki S, Miyoshi N, Kawabata K, Yasuda M, Shimoi K. Quercetin-3-O-glucuronide inhibits noradrenaline-promoted invasion of MDA-MB-231 human breast cancer cells by blocking $\beta 2$-adrenergic signaling. Arch Biochem Biophys 2014;557: 18-27.

7. Balligand JL. Cardiac salvage by tweaking with beta-3-adrenergic receptors. Cardiovasc Res 2016;111:128-33.

8. Cannavo A, Koch WJ. Targeting $\beta 3$-adrenergic receptors in the heart: selective agonism and $\beta$-blockade. J Cardiovasc Pharmacol 2017;69:71-8. 